\title{
Establishing an Effective Nuclear Regulatory Regime: A Case Study of South Africa
}

\author{
Mosebetsi Leotlela ${ }^{1,2}$ \\ ${ }^{1}$ School of Physics, University of the Witwatersrand, Johannesburg, South Africa \\ ${ }^{2}$ Regulations and Licensing, Koeberg Nuclear Operating Unit, Eskom, Megawatt Park, Sunninghill, Johannesburg, South Africa
}

Email address:

leotlem@gmail.com

To cite this article:

Mosebetsi Leotlela. Establishing an Effective Nuclear Regulatory Regime: A Case Study of South Africa. Science, Technology \& Public Policy. Vol. 5, No. 1, 2021, pp. 1-18. doi: 10.11648/j.stpp.20210501.11

Received: January 4, 2021; Accepted: January 25, 2021; Published: March 4, 2021

\begin{abstract}
This research is aimed at providing insight into various nuclear regimes for countries that are looking to start a nuclear energy programme but have yet to develop such regimes, as well as those with a well-established nuclear programme. It will also evaluate the value of independence of nuclear regulators with regards nuclear safety whether independence on its own is of any value to the society or the nuclear regulator needs to be more effective in giving effect to the objective and mandate it was established for. Based on the fact that there is currently no yardstick available to measure the effectiveness of the nuclear regulator in carrying out its functions, a number of pointers are listed which failed will indicate the ineffectiveness of the nuclear regulators in protecting the public, environment and the property from the harmful effects of radiation. It will also highlight the value of flexibility in nuclear licensing in order to find the right fit between the nuclear regulatory circumstances and not sticking to the design of the nuclear regulatory regimes when they are not relevant. In addition, this paper will indicate the advantages and disadvantages of various regulatory regimes applicable to the nuclear regulatory authority, and most importantly show the fundamental difference between 'as low as reasonably achievable, (ALARA), economic and social factors being taken into account' and 'as low as reasonably practicable' (ALARP), and why these two cannot be used interchangeably.
\end{abstract}

Keywords: Prescriptive Nuclear Regulatory Regime, Non-prescriptive Nuclear Regulatory Regime, System-Based Nuclear Regulatory Regime

\section{Introduction}

In the past two decades, there has been in a significant increase in interest in nuclear power as a result of international pressure to reduce $\mathrm{CO}_{2}$ emissions which is Target no 1 of 8 of the UN Secretariat Climate Action Plan (Absolute and Per Capita reduction of $25 \%$ by 2025 and $45 \%$ by 2045). And to meet the United Nations (UN) 2020-2030 climate change target [4]. As a result, a number of countries have initiated massive nuclear power programmes so as to sustain their energy security while meeting the UN climate change targets before the deadline. South Africa is no different; in the Integrated Resource Plan (IRP) 2010-30 9600 MW of nuclear energy were included in the country's energy mix, specifically stating that it would consist of $6 \mathrm{x}$ $1600 \mathrm{MW}$ reactors [5]. Some of the countries that have seen an increase in the construction of nuclear power stations are listed in Table 1, where the full names of the abbreviations in the table refer are as follows: BWR (Boiling water reactor), FNR (Fast neutron reactor) HTGR (High temperature gascooled reactor), PHWR (Pressurised heavy water reactor), PWR (Pressurised water reactor).

Table 1. Reactors under construction by region, year-end 2018 (change since 2017) [6].

\begin{tabular}{llllllll}
\hline \multicolumn{1}{l}{ BWR FNR } & HTGR & PHWR & PWR & Total \\
\hline Asia & 4 & 1 & 1 & 4 & $26(-4)$ & $36(-4)$ \\
Eastern Europe \& Russia & & & & & $10(-1)$ & $10(-1)$ \\
North America & & & & & 2 & 2 \\
South America & & & & & 2 & 2 \\
Western \& Central Europe & & & & & $5(+1)$ & $5(+1)$ \\
Total & 4 & 1 & 1 & 4 & $45(-4)$ & $55(-4)$ \\
\hline
\end{tabular}

Some of these countries include those in which nuclear power energy is relatively new, while others have had nuclear energy for many years but need to build more power 
stations because of the demand in energy supply as shown in Table 2. One of the countries which had its first nuclear power plant commissioned in 2020 is the United Arab Emirates.

Some of the countries with construction projects that started as recently as 2018 are listed in Table 2 and comprise a combined capacity of $6279 \mathrm{MW}_{\mathrm{e}}$.

Table 2. Reactor construction started in 2018.

\begin{tabular}{lllll}
\hline Reactor & Country & $\begin{array}{l}\text { Nett Capacity } \\
\text { (MWe) }\end{array}$ & $\begin{array}{l}\text { Start of } \\
\text { Construction }\end{array}$ & Reactor type \\
\hline $\begin{array}{l}\text { Akkuyu-1 } \\
\text { Hinkley }\end{array}$ & Turkey & 1114 & 3 April 2018 & $\begin{array}{l}\text { PWR } \\
\text { (VVER) }\end{array}$ \\
$\begin{array}{l}\text { Point C-1 } \\
\text { Kursk II-1 }\end{array}$ & Russia & 1115 & $\begin{array}{l}\text { 11 December } \\
\text { 2018 }\end{array}$ & $\begin{array}{l}\text { PWR } \\
\text { PWR }\end{array}$ \\
Rooppur 2 & Bangladesh & 1080 & 20 April 2018 & $\begin{array}{l}\text { (VVER) } \\
\text { PWR }\end{array}$ \\
Shin Kori 6 & South Korea & 1340 & 14 July 2018 & $\begin{array}{l}\text { PWVR) } \\
\text { (VVERtember }\end{array}$ \\
\hline
\end{tabular}

In countries where reactors are already operational, there is still a small fraction of operable nuclear capacity that does not generate electricity in a calendar year for various technical reasons e.g. maintenance or refurbishment shut down, etc. Nevertheless, when all the technical problems are resolved capacity increases, adding to the installed ${ }^{1}$ as well as sent-out capacity ${ }^{2}$. For example, since 2011 the majority of the Japanese reactor fleet has been awaiting restart. In 2018, four Japanese reactors were restarted, joining the five reactors that had already been restarted in previous years.

There is no doubt that the increase in the number nuclear power stations is not without risk owing to the radiationinduced health risks emanating from the operation of nuclear power stations and from spent fuel storage. To minimise health risks emanating from nuclear plants, it is prudent that the national government of the country establish an effective nuclear regulatory regime with all the necessary authority (legal existence and accompanying powers and authority) to regulate and oversee any operation/handling of nuclear matter.

Countries that are installing nuclear power stations for the first time should realise that following the nuclear option for the very first time is a massive undertaking and every state organ has a role to play.

\section{The Role of the National Government in a Nuclear Regulatory Regime}

If the nuclear project is to be successful and safe, the national government of the country concerned will have to

\footnotetext{
1 "Installed capacity" refers to the production capacity of a plant based on either on its related design (aka nameplate) capacity or the actual (practically measured) capacity.

2 "Sent-out capacity" refers to electricity output measured at the generating unit outlet terminal having taken out the power consumed by the unit auxiliaries and losses in transformers considered integral parts of the unit.
}

establish a nuclear regulatory authority to regulate and oversee any operation/handling of nuclear matter, as mandated by requirement 3 of the General Safety Requirements No. GSR Part 1 [7] which reads as follows:

The government, through the legal system, shall establish and maintain a Nuclear Regulatory Authority, and shall confer on it the legal authority and provide it with the competence and the resources necessary to fulfil its statutory obligation for the Nuclear Regulatory control of facilities and activities.

The government will determine the specific functions of the nuclear regulatory authority and the delegation of authorities and responsibilities. For example, the government establishes laws and adopts policies pertaining to nuclear safety, whereas the nuclear regulatory authority develops strategies and promulgates regulations for implementing such laws and policies. In addition, the government establishes laws and adopts policies specifying the responsibilities and functions of different governmental entities in respect of safety and emergency preparedness and response, whereas the nuclear regulatory authority establishes a system to give effect to these policies.

The nuclear regulatory authority, as delegated by the government, will be charged with the responsibility for implementing policies by means of a nuclear regulatory programme and a strategy, which are set out in its regulations or in national standards. In order to achieve these, it is important that the principle of independence of the nuclear regulatory authority be adhered to, which reads:

The government shall ensure that the Nuclear Regulatory Authority is effectively independent in its safety related decision making and that it has functional separation from entities having responsibilities or interests that could unduly influence its decision making.

The nuclear regulator must therefore be independent from political interference, financial budgetary constraints or financial blackmail, as well as displaying technical resourcefulness and independence from industry influence (see Requirement 4 of The Characteristics of an

Effective Nuclear Regulator [7, 8]. When nuclear regulators are financially and technically dependent on entities that have an interest in the business, they are prone to sabotage, blackmail or even bullying by these entities.

With regard to technical independence, if the regulator is not technically independent, i.e. does not have the skills to perform technical analyses/review of a certain scientific discipline, there is the possibility that the licensee may submit a report that is technically complicated but when the regulator reviews this submission $\mathrm{s} / \mathrm{he}$ will not be in a position to make sound technical comments because he/she is not competent to handle such complicated matters. A lack of technical know-how on the part of the nuclear regulator can result in the use of external consultants who come at a huge cost. This cost is (i) often passed on to the licensee in spite of the licensee paying nuclear licence fees, which further increases the financial burden on the licensee and (ii) because the regulator cannot do this task him/herself, which is why it 
is outsourced to consultants, s/he will still not be in a position to make a proper technical review when receiving a report from consultants, because they did not have the skills to do it in the first place. Consequently, the regulator pays a lot of money for work it cannot use because it does not understand it; this defeats the purpose of the regulator as an intelligent customer $^{3} /$ knowledgeable customer $^{4}$ (8) and, as a result, public safety may be compromised.

\subsection{The Purpose of the Regulator}

The fundamental objective of a nuclear regulator is to ensure that activities related to the peaceful use of nuclear energy are carried out in a safe manner, in accordance with international safety principles and with full respect for the environment [7-9]. This is often reflected in the values, mission and vision statements of many nuclear regulators around the globe and is generally how many nuclear regulators promote their roles of protecting humans and nonhumans and the environment (see International Commission on Radiological Protection-Publication 108 (ICRP 108) [10] against the radiation-induced health risks associated with nuclear activities and in respecting international accords. This obligation has been deliberated by the International Atomic Energy Agency (IAEA) in its Fundamental Safety Principles, where Principle 2 states that: "The government shall establish and maintain an appropriate governmental, legal and Nuclear Regulatory framework for safety within which responsibilities are clearly allocated."

In spite of the nuclear regulatory authority having been established to oversee the safety of nuclear facilities, it is important to emphasise that although the mission of the nuclear regulatory authority is to provide oversight on nuclear safety, the prime responsibility for the safety of a nuclear installation has to remain with the licensee or plant operator [8].

Accordingly, it stands to reason that the independence of a nuclear regulator is key to its ability to carry out its mandate effectively and objectively; and to that effect the nuclear regulator must possess the following qualities $[7,8]$ :

1) have public safety as its primary focus

2) be clear about its nuclear regulatory roles and responsibilities, its purpose, mandate and functions

3 ) be independent in nuclear regulatory decision-making from any undue influence on the part of the nuclear industry and those sectors of government that sponsor this industry

4) have technical competence at its core, with other competencies built upon this fundamental and essential requirement

5) be open and transparent in its regulations and decisions

6) have a nuclear regulatory framework and requirements

3 The regulator should maintain supervision over assistance from external experts and be an intelligent customer capable of properly understanding and independently evaluating the expert advice [8].

4 A customer of services who knows what is required, who fully understands the need for the contractor's services, and who can specify the requirements, then supervise the work and technically review the output [12] that are clear and easily understood by all stakeholders

7) make clear, balanced and unbiased decisions and be accountable for those decisions

8) have a strong organisational capability in terms of adequate resources, strong leadership and robust management systems

9) perform its nuclear regulatory functions in a timely and efficient manner

10) have and encourage a continuous self-improvement and learning culture, including the willingness to subject itself to independent peer reviews.

\subsection{Principles for an Effective Nuclear Regulator}

After a nuclear regulatory authority has been established, it has to perform the function it was established to do effectively, and not leave it up to the licensee to decide how and what to do, letting life continue as normal as if there were no nuclear regulator, adopting the a laissez-faire leadership style. The value and effectiveness of the nuclear regulator is judged by the difference it makes to the public on matters relating to public safety from undue radiological health risks and in protecting the proper. That is, it must make an impact in as far as nuclear safety matters are concerned, and be effective and efficient in its functions. To that effect it must possess the following fundamental primary principles which are the basis of conduct from which all nuclear regulatory authority codes of conduct should be derived [8]:

a) Focus on public safety and safety culture

Central to the very existence of a nuclear regulator is public safety. However, as was stated in Section 2.1 that does not exonerate the licensee from full responsibility for the safety of nuclear facilities operating in that country [8]. In addition to all the principles and attributes that the nuclear regulator has, it must also be robust in its entirety. The International Nuclear Safety Advisory Group-4 (INSAG-4) defines a safety culture as follows:

Safety culture is that assembly of characteristics and attitudes in organisations and individuals which establishes that, as an overriding priority, nuclear plant safety issues receive the attention warranted by their significance [11].

b) Independence

The basic requirement for an effective nuclear regulator is independence, as set out in GSR-Part 1. Requirement 4 [7] and in Article 8 of the Convention on Nuclear Safety. According to these texts, the function of the nuclear regulatory authority shall be effectively separated from those of any other authority or organisation concerned with the promotion or utilisation of nuclear energy or having other interests. Functional separation forms the basis and the conditions for independent nuclear regulatory decisionmaking that is free from undue influence. This includes making and being seen to make independent, clear, balanced and unbiased nuclear regulatory decisions.

In order to ensure that the nuclear regulatory authority is effectively independent from undue influence in its decisionmaking, several elements are of the utmost importance. 
These elements include [7, 12]:

1. Political independence

i) The nuclear regulator should have the legislated power and authority to make independent nuclear regulatory judgements and nuclear regulatory decisions within its field of competence for routine work and in crisis situations

ii) Have the ability to take nuclear regulatory decisions and enforcement measures founded on objective safety-related requirements

iii) $\mathrm{Be}$ empowered to give independent advice to government departments and governmental bodies on matters relating to the safety of facilities and activities

2. Financial independence

i) The nuclear regulator should be provided with adequate financial resources, reliable funding and staffing for the proper and timely discharge of its assigned responsibilities

ii) $\mathrm{Be}$ provided with a clearly defined financing mechanism and budget allocation process within the national framework

3. Technical independence

i) The nuclear regulator should possess technical and scientific competence needed to perform its function without relying on consultants and the capacity to make independent decisions

ii) Must have unlimited access to independent scientific and technical support.

\section{c) Competence}

In order for the nuclear regulatory organisation to be effective, have credibility and be trusted, it must have as a minimum the following core competencies [12, 13]: technical know-how, i.e. adequate scientific/engineering skills, and should understand its legislative basis and its legislative powers and authority (see Table 3 ).

Table 3. Competence matrix.

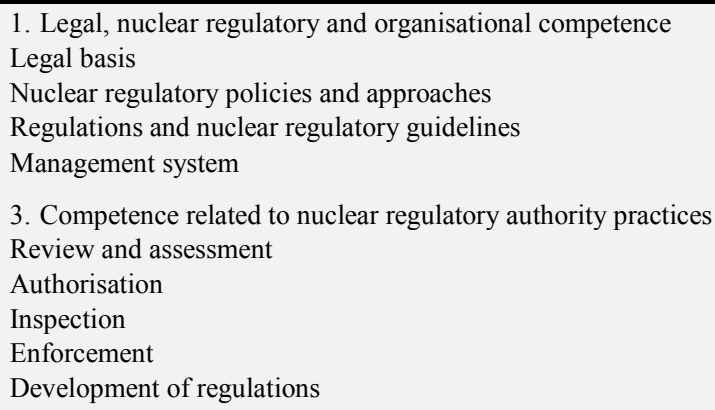

\section{Categories of Nuclear Regulatory Regimes}

According to scholars of law, public administration and governance, regulatory regimes in general vary quite widely $[2,14-16]$. For that reason and for similar theoretical, methodological and empirical reasons, it is important to analyse and understand the theory underlying these differences before a selection of these options is adopted.

According to May [2, 16], in order to conceptualise a regulatory regime one may think of it as a means for achieving regulatory goals. Nuclear regulatory regimes are no different, like other regulatory regime in other economic sectors such as the financial sector, they comprise an institutional structure and assignment of responsibilities for carrying out regulatory functions that ensures that the overall objective of nuclear safety is achieved [2]. According to Levi-Faur [15], the notions of "regulatory regime" and "international regulatory regime" may be defined as the "principles, norms, rules, and decision-making procedures around which actors' expectations converge in a given issuearea" [15]. These institutional structures are made up of rules that prescribe expected behaviours or outcomes, standards that are benchmarks against which compliance
2. Technical disciplinary competences

Basic science and technology

Applied science and technology

Specialised science and technology

4. Personal and behavioural competence

Analytical thinking and problem solving

Personal effectiveness and self-management.

Communication

Teamwork

Managerial and leadership competence

Safety culture

can be measured, a mechanism for determining the degree of nuclear regulatory compliance, and sanctions for failure to comply with the rules.

Given that there is a variety of ways in which the rules and standards can be constituted and responsibilities for nuclear regulatory function can be assigned, there is no definitive categorisation of nuclear regulatory regimes. Accordingly, these regimes may be broadly classified into two main categories each on either end of the nuclear regulatory regime continuum: prescriptive and non-prescriptive regimes. Between these two extremes there is a variety of hybrid nuclear regulatory regimes with different combinations of the main ones (refer Figure 1 and Table 4). If a nuclear regulatory policy is biased towards either side, it is a reflection of a governmental role in and commitment to setting forth regulations that are either prescriptive or nonprescriptive and making provision to enforce them. Because prescriptive and non-prescriptive regimes lie on opposite ends of the continuum, they differ in respect to the nature of the rules and standards and the means for gauging adherence to them. Prescriptive regimes are highly prescriptive in nature, telling nuclear operators and individuals what to do and how to do it to achieve compliance with nuclear regulations, which is what other scholars regard as command and control. Nuclear regulatory enforcement for prescriptive regulation emphasises adherence to the prescribed rules and 
standards, which in turn is presumed to provide acceptable

outcomes in meeting nuclear regulatory goals.

Table 4. Nuclear regulatory regimes.

\begin{tabular}{|c|c|c|c|}
\hline & \multicolumn{3}{|l|}{ Nuclear regulatory regime } \\
\hline & \multirow[b]{2}{*}{$\begin{array}{l}\text { Prescriptive nuclear } \\
\text { regulatory regime }\end{array}$} & \multicolumn{2}{|c|}{ Non-prescriptive nuclear regulatory regime } \\
\hline & & $\begin{array}{l}\text { System-based nuclear regulatory } \\
\text { regime }\end{array}$ & $\begin{array}{l}\text { Performance-based nuclear } \\
\text { regulatory regime }\end{array}$ \\
\hline Nuclear regulatory focuses & $\begin{array}{l}\text { Rule-based or prescribed action } \\
\text { in the form of regulations }\end{array}$ & Process or system-based & Outcome/result-based \\
\hline Compliance determination & Adherence to prescribed actions & Acceptable production process/system & Achievement of desired results \\
\hline Nature of rules and standards & $\begin{array}{l}\text { Very particular/specific and } \\
\text { detailed specifications }\end{array}$ & Process-oriented specifications & Goal-oriented outcome specifications \\
\hline $\begin{array}{l}\text { Basis for achieving nuclear } \\
\text { regulatory goals }\end{array}$ & $\begin{array}{l}\text { Adherence to prescribed actions } \\
\text { presumed to meet goal }\end{array}$ & $\begin{array}{l}\text { Appropriate systems controls are } \\
\text { designed to meet required goals }\end{array}$ & $\begin{array}{l}\text { Nuclear regulatory goals are embedded } \\
\text { in the results orientation }\end{array}$ \\
\hline
\end{tabular}

The difficulty with prescriptive regulation is that if a nuclear accident happens when performing a certain task, for example fuel loading following a regulator's sanctioned procedure/process, the legal consequences could be dire if it can be proven that (i) the accident was caused solely by the incorrect procedure and not human error on the part of the licensee, (ii) the accident could have been avoided if the regulators had not prescribed the process/procedure and the licensee had followed their own process to perform the task. Because of this, scholars of governance, public administration and nuclear licensing argue that unreasonable regulations impose needless burdens on nuclear operators. Such factors are a major cause of discontent and reluctance to implement prescriptive regulations and are the key reasons why nuclear regulatory transformation to less prescriptive regime is sought. These are also some of the reasons why countries like the UK are non-prescriptive and also why there is an increase in migration toward non-prescriptive regimes and an increase the 'births' of hybrid variants of the two main regulatory approaches, e.g. risk-based, principle-based regulations etc. The rationale for this transition rests on the rigidity of prescriptive regulations and also their shortcomings; they cannot keep up with the safety requirements in nuclear plants which are too complicated for prescribing effective nuclear regulatory fixes. Instead, adherents to the system-based approach argue that nuclear regulatory goals can be achieved by instituting appropriate systems for monitoring production processes [2, 14]. In practice, it rarely happens that a 'pure' prescriptive or nonprescriptive approach is implemented; instead various 'hybrid' approaches are utilised which combine elements of both approaches to regulation. For example, even back in the early days of the Council for Nuclear Safety (CNS) when it was established in South Africa, the approach was not entirely non-prescriptive because even then it had its own licence guides (LG) which prescribed a certain ways of doing things; hence, it had a certain element of prescriptive regulation. Because of this, it is possible to characterise applications as either 'more prescriptive-like' or 'more nonprescriptive-like'.

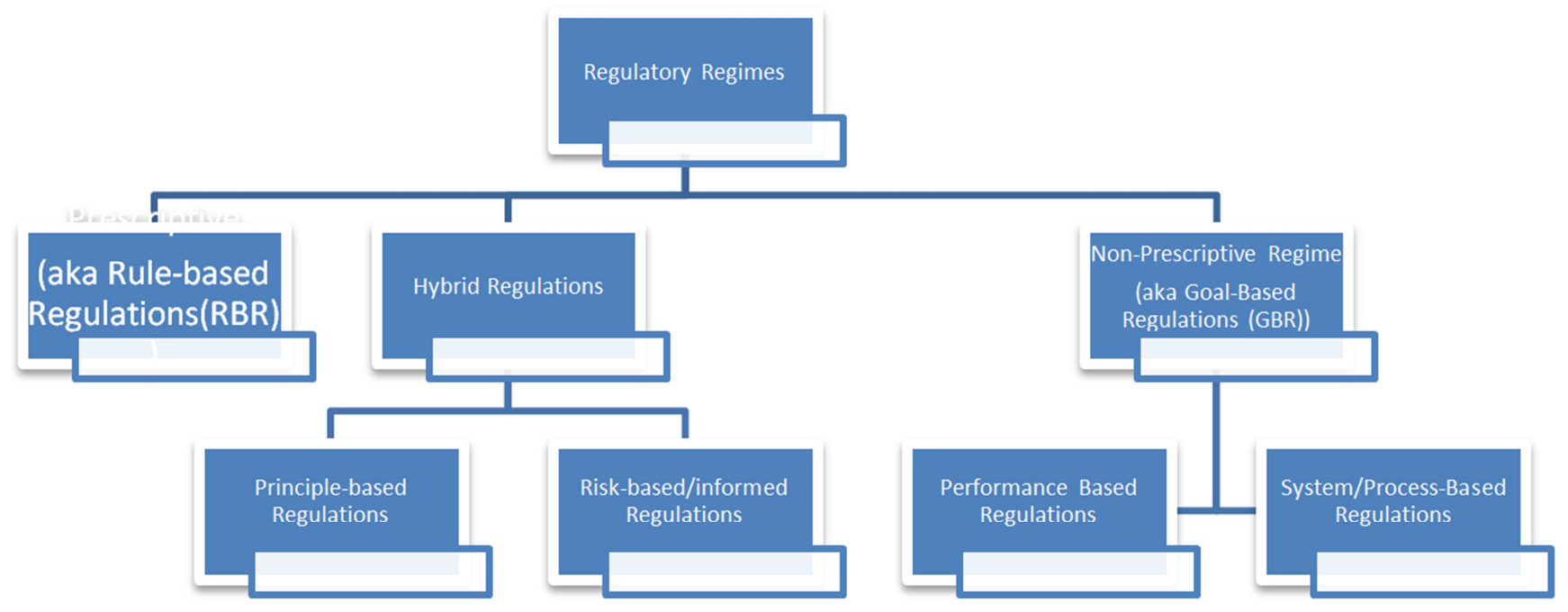

Figure 1. Interrelationship among nuclear regulatory regimes.

The first port of call for a change from a prescriptive to a non-prescriptive regime is the application of a system-based regime, which has also been labelled a process-based or a management-based regulation.
Secondly, nuclear regulatory reform should emphasise nuclear regulatory outcomes (i.e. be goal/target oriented, rather than being system-process driven) under what has been labelled performance-based regulation (PBR). This approach 
emphasises regulating the results/goals rather than the processes, while leaving it up to the licensee to determine how best to achieve the desired results [2, 14, 16]. The central change under the performance-based approach is the attention paid to outcomes as part of nuclear regulatory rules and standards. The focus of the nuclear regulator is on whether the desired level of performance has been obtained, as defined by the relevant performance-oriented rules and standards.

Over the past couple of decades the effectiveness of a nuclear regulatory regime has become an increasingly popular area of research owing to a number of nuclear accidents that have occurred, including Three Mile Island (TMI) in 1979, Chernobyl in 1986 and, recently, the Fukushima nuclear accident in 2011. These led scholars of regulatory governance and public administration to ask questions about whether it is the independence of the regulatory authority that is of concern here or whether it is the effectiveness of regulations governing the nuclear industry which itself needs to be regulated that is the problem leading to these nuclear accidents. I strongly believe that somehow we need to develop some means to evaluate and regulate the effectiveness of the regulatory regime or the regulatory authority if we are to mitigate such nuclear incidents/accidents. In South Africa, one of the lessons learnt from the TMI and Chernobyl accidents was to upgrade nuclear emergency planning from an ad hoc, back-bench function to a fully-fledged section (which I have been appointed to) of the radiation protection department within the CNS dedicated to emergency planning (see Figure 6). Because of this, strengthening the nuclear regulatory regime became more important than ever. Many scholars were of the opinion that the solution to this was to functionally separate the nuclear regulatory functions from the operational/production-related functions of a licensee, eventually repositioning the regulator to become an independent juristic person, as has been the case in South Africa for the past couple of decades. The process to reduce these accidents not only relies on the independence of the nuclear regulator but also on the effectiveness ${ }^{5}$ of the nuclear regulatory regime adopted in that country.

\subsection{Prescriptive Nuclear Regulatory Regimes}

Nuclear regulatory policies differ from country to country, depending on the culture, social, economic and governmental systems of the country. In a prescriptive regime (also known as command and control), the principles are quantitative ${ }^{6}$ the requirements for methodologies, standards and quality assurance are prescribed by the nuclear regulator and the licensee must merely comply with them. In addition to the

5 Regulatory effectiveness is about ensuring that nuclear facilities are operated safely.

6 Quantitative data can be measured more or less accurately because it contains some form of magnitude, usually expressed in numbers. Mathematical procedures can be used to analyse the numerical data. These can be extremely simple such as counts or percentages, or more sophisticated such as statistical tests or mathematical models. nuclear regulatory guidelines, methods acceptable to the nuclear regulatory authority are provided that the licensee must follow when implementing specific parts of the regulations. Many of these regulations are highly prescriptive, telling the licensee and the individuals concerned what to do and how to do it. Prescriptive regulation tends to be highly particularistic in specifying required actions and standards for adherence [1]. One of the organisations that have implemented prescriptive regulations successfully that work is the US Nuclear Regulatory Commission (USNRC).

\subsubsection{Shortcomings of Prescriptive Nuclear Regulatory Regimes}

Nuclear regulatory regimes have their shortcomings; six shortcomings have been identified for prescriptive nuclear regulatory regimes, namely: (i) expensive and ineffective regulatory strategies; (ii) inflexible nuclear regulatory strategies that encourage adversarial enforcement; (iii) legal constraints on the subjects, procedures and scope of nuclear regulatory discretion; (iv) licensees' resentment, which leads to noncompliance or "creative compliance" [15]; (v) strict regulation that often presents an obstacle to innovation; and (vi) regulation that often serves to set the lowest common denominator for licensees to follow rather than supplying incentives for improved standards.

In South Africa, there has been a noticeable gradual migration from a non-prescriptive regulatory regime, which was enforced in the early days of the CNS, towards a prescriptive regulatory regime, as the National Nuclear Regulator (NNR) now uses hybrid regulatory approaches which in some cases are performance-based and in others system or process based. In a hybrid regulatory regime, because of the hybrid nature of the approach, the nuclear regulatory decision, which leans largely to the prescriptive side rather than the non-prescriptive side, is often responsible for the controversy/conflict that a nuclear regulator experiences with its licensees and stakeholders.

South Africa is no exception from this controversy; one of the classical examples of legal challenges resulting from lack of buy-in/public acceptance of some of the regulations is the case of McDonald vs. Department of Mineral and Energy (DME) [17] in which the DME used RD-0015 ${ }^{7}$ to try and prevent further spatial development within the $16 \mathrm{~km}$ zone dedicated to the emergency planning zone (EPZ) with a view to ensuring that the emergency preparedness and response plans remained viable and effective; as such, there should be no more development because this would impede evacuation in the case of a nuclear accident where evacuations are recommended. In court papers

Eskom said that, in the event of an accident, an increase in the adjacent population of 4400 people due to the proposed development would aggravate the potential radiological risk and also increase the evacuation time. It would also compromise the functionality of mass care centres; require additional radiological equipment and

\footnotetext{
7 Regulatory Document no 15.
} 
resources; and increase the accommodation needed for people exposed to radioactivity [17].

The court found that section 38 (4) of the National Nuclear Regulator Act [18] conferred on the minister the power to make regulations, on the recommendation of the board of the regulator and in consultation with the relevant municipalities, on the development surrounding any nuclear installation to ensure the effective implementation of any applicable emergency plan. In purporting to exercise these powers, the minister on March 52004 implemented regulations that gave the regulator the power to lay down specific requirements to control and monitor property developments within the formal emergency planning zone. "The judges found that the minister's delegation of power to the regulator to issue specifications was unauthorised and that she was only permitted to delegate that power to the director-general of her department. The judges said that if the relevant regulation was set aside, it was axiomatic that it would render the regulator's requirements unlawful as well since any validity they might have had could only be derived from the minister's regulation" [17].

This case highlighted a combination of factors:

a) incorrect execution of nuclear regulation that encourage adversarial enforcement

b) legal constraints on the subjects, procedures, and scope of nuclear regulatory discretion which are characteristics of a prescriptive regime are likely to result in conflict between the licensee and the licensor/regulator

c) lack of public participation and the impact there of which often results in resentment rather than public acceptance

d) inflexibility of regulations characteristic of a prescriptive regime.

e) Ineffective/inadequate legal advice to the regulator because the legal department should have been able to foresee this.

\subsubsection{Advantages of Prescriptive Nuclear Regulatory Regimes}

For the Nation Nuclear Regulator, there are a number of advantages of using the prescriptive regime.

1. In prescriptive regulatory regime, all safety targets (dose rates, health risks, safety performance) are prescribed by the regulator and well documented. The licensee knows exactly what is expected of him/her and what the nuclear regulator requires for the licensee to meet safety and regulatory acceptance.

2. In a process-based regulatory regime, the regulator stipulates/prescribes the process to be followed to achieve the safety targets.

3. There is less subjectivity which is often seen in nonprescriptive regulatory regime which is often characterised by different staff members of the same regulatory authority giving different assessment outcomes of the same submission.

4. The cost of unnecessary clarification workshops are reduced because all the requirements are documented.

5. There is less reliance on highly skilled engineers/scientist for their "expert judgement" as all the information/requirements are document and available to everyone.

\subsection{Non-prescriptive Nuclear Regulatory Regime}

Non-prescriptive nuclear regulatory regimes, on the other hand, are not as controlling or as particularistic as prescriptive regimes. The nuclear regulatory principles involved are largely qualitative $e^{8}$ in nature, except for certain parameters/cases such as specifying dose or risk limits $[2,3$, $15,19]$. The licensee must comply with these principles, but may choose its own methodology for how it will do so.

European regulations are generally less prescriptive than those used in the USA. There is, however, some degree of variation among European countries, with some countries choosing to adopt a non-prescriptive licensing regime, the UK being one of them. In the UK, nuclear licensing is crafted in such a way that the Health and Safety Executive (HSE) sets regulatory targets, be it effective dose or health risk limit, but it is entirely up to the licensee to demonstrate that it complies with them and it can take whatever action it so chooses to meet these targets. The execution of this principle is well captured in the UK Office for Nuclear Regulation (ONR) in which it is explicitly stated that:

The UK generally operates a goal-setting regime rather than the more prescriptive, standards-based regimes applied in some other countries. This means that ONR sets out its Nuclear Regulatory expectations, and requires licensees to determine and justify how best to achieve them. This approach allows an operator to be innovative and to achieve the required high levels of nuclear safety by adopting practices that meet its particular circumstances. It also encourages continuous improvement and the adoption of relevant good practices [20].

As stated previously, in the UK the nuclear licensee merely has to demonstrate the equivalent safety of its preferred approach or argue that the costs required to execute HSE recommendations are excessive [21]. Approaches to securing safety can therefore differ from licensee to licensee even though they are in the same country, as long as the nuclear regulatory safety goal is achieved. This emphasises one important goal in nuclear regulations: nuclear safety is not the responsibility of the nuclear regulator; it is the responsibility of the licensee/nuclear plant operator. This is consistent with Requirement 6 of the Governmental, Legal and Nuclear Regulatory Framework for Safety, which reads: "The government shall stipulate that compliance with regulations and requirements established or adopted by the Nuclear Regulatory Authority does not relieve the person or

\footnotetext{
8 Qualitative data cannot be accurately measured and counted, and are generally expressed in words, "fair", "reasonable", "suitable", "achievable", rather than numbers. The most common qualitative phrases used in the nuclear industry that are often associated with deterministic safety analyses are "Safe Enough", "As Low As Reasonably Achievable (ALARA)" and "As Low As Reasonably Practicable (ALARP)".
} 
organization responsible for a facility or an activity of its prime responsibility for safety" [7]. This principle is one of the fundamental founding pillars of the UK regulatory approach, of which John Jenkins, the Chief Executive Officer of the ONR is proud, as seen in his 2016 version of "A guide to Nuclear Regulation in the UK":

ONR is not responsible for delivering a safe and secure nuclear industry; this is the responsibility of the nuclear industry itself. Our role, captured in our mission statement, is to provide efficient and effective regulation of the nuclear industry, holding it to account on behalf of the public [20].

Another important consideration is that the whole domain of the HSE safety culture is based on the "ALARP" principle - as low as reasonably practicable - which is explicit about the cost of countermeasures. In recent years, the UK has developed a new regulatory regime which it calls a permissioning ${ }^{9}$ approach to safety, rather than a more mechanistic checklist approach.

The term 'reasonably practicable' in UK law means that measures to reduce risk should be taken unless the sacrifice is grossly disproportionate to the benefit. The term 'gross disproportion' is therefore another concept that needs to be understood in relation to ALARP. Grossly disproportionate should be taken into account in deciding whether risks are ALARP when comparing the benefits of implementing a measure to reduce risk against the 'cost' of that measure ('cost' being used to mean the 'sacrifice' involved and including factors such as time and effort, as well as money). A measure will be reasonably practicable if its 'costs' of implementation do not outweigh the benefits by a grossly disproportionate amount. The ALARP process is therefore aimed not at balancing the costs and benefits of measures but, rather, of implementing measures except where they are ruled out because they involve grossly disproportionate sacrifices (refer Figure 4).

The related notion of "as low as reasonably achievable (ALARA), economic and social factors being taken into account" [22] has currency in South Africa and North America, particularly in Canada, where such considerations have been adopted into legislation.

\subsubsection{System-based Nuclear Regulatory Regime}

System-based regulations are known as either 'management-based', 'enforced self-regulation', 'mandated self-regulation', 'reflexive' regulation, or 'process-based', depending on the background of the author or reader [2, 14]. In this article I use terms system-based and process-based interchangeably because of their relevance in the nuclear licensing environment in which I have spent the past 20 years of my career. Although this basic approach has been noted

\footnotetext{
9 Regulatory regimes requiring safety submissions and/or a licence are referred to as 'permissioning regimes'. The ONR's approach to such regimes is set out in the HSE's Permissioning Policy Statement, published in 2003. Most safety submissions to the ONR arise from the UK Nuclear Installations Act 1965 (NIA) licence requirements, but are also required for Generic Design Assessment (GDA) as well as for other regulations.
}

and described by socio-legal scholars of regulation, virtually no attention has been given to management-based approaches in the broader literature on nuclear regulatory instrument choice [14].

In a production environment such as a fuel fabrication, fuel enrichment or, isotope production plants the type of nuclear regulatory regime adopted depends on the stage of production, as indicated in Figure 2.

At the core of a process-based regime is the regulator's recommended process, that is, the methodology that must be followed when performing a given task rather than dictating particular nuclear regulatory outcomes/results. In particular, the nuclear regulatory framework will contain certain requirements for the process to be followed with an understanding and an expectation that this process will lead to the expected results/goal. Typically, process-based regulation will require the identification of risks that might materialise, which must then be assessed and addressed through appropriate measures. The nuclear regulatory framework will usually require documentation of the process in the form of risk management plans [23]. For example, the regulator may recommend a process for determining the magnitude of the emergency planning zone (EPZ) and the corresponding protective action for a class of nuclear accidents to ensure that the public is safe, instead of prescribing the magnitude of the EPZ. This includes determining the source term from all anticipated design-basis and beyond design-basis accidents and, based on these analyses, select an enveloping source term which encompasses source terms from all nuclear accidents analysed which then will serve as the basis for the EPZ. From this it is clear that in the regulator may not prescribe the magnitude of the EPZ; it is up to the licensee to demonstrate safety by following the above process and derive a technology-specific EPZ, and submit that as part of the safety case to the nuclear regulator for approval.

Process-based regulation is particularly useful in cases where the risks, for example the stochastic health effects of radiation, which are sought to be prevented are potentially substantial but are uncertain and diffuse. In addition, it also ensures that by applying the same process to a variety of different situations (e.g. determining the enveloping source term for all prospective new reactor designs as a basis for EPZ) a consistent approach is attained to ensure that no member of the public is exposed to undue radiological health risks from the operation of a nuclear reactor.

\subsubsection{Performance-based Nuclear Regulatory Regime}

Performance-based regulation (PBR) corresponds to the case where a specified safety target must be reached, regardless of the technical solutions put into place. Compliance is assessed by examining whether the proposed design or processes/systems achieve a satisfactory risk level, and then by monitoring whether the operator follows its own recommendations and that performance corresponds to the expected level of safety $[19,24]$.

The PBR is an alternative nuclear regulatory framework 
designed to better align the financial interests and safety performance of licensees with the public and consumer interests at the heart of benefits. A PBR framework rewards utilities for achieving well-defined outcomes as opposed to incentivising capital investment (inputs), which is the primary driver today of utility revenue and profits. Nuclear regulatory reforms, such as $\mathrm{PBR}$, have the potential to change the way licensees, customers and third-party providers generate, deliver and use energy [24].

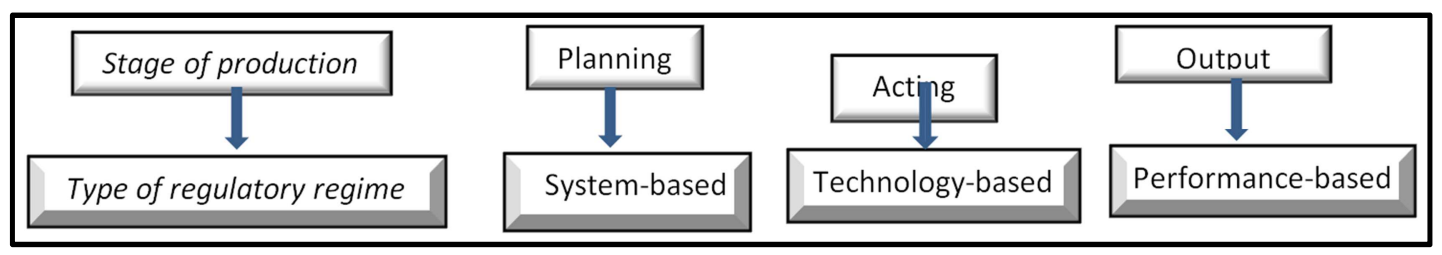

Figure 2. Changes in nuclear regulatory regimes with organisational production stage.

According to Maddocs [23], if one is to define PBR more precisely, one has to start by distinguishing the four main ways in which performance can be incorporated into regulation:

a. Performance can be used as a basis for evaluating nuclear regulatory programmes and their respective agencies (evaluation or management).

b. Performance can constitute a criterion for allocating enforcement and compliance resources (targeting).

c. Performance can trigger the application of differentiated or tiered nuclear regulatory standards (tracking).

d. Performance can form the basis for legal or nuclear regulatory commands (standards).

\subsection{Hybrid Regime}

As previously stated, a hybrid regulatory approach is a 'compromise' between a prescriptive and a non-prescriptive regime, giving more sophisticated industries like the nuclear industry the ability to innovate and adapt, while at the same time giving clear guidance to licensees that simply want to know "what do I do?" Which of the two extremes regimes tend to favour varies from country to country, depending on the resources and socio-political conditions. Some of such hybrid regimes are described below:

\subsubsection{Principle-based Regime}

Principle-based regulation relies upon principles as the basis for driving the achievement of regulatory outcomes. This is similar to PBR in the sense that it does not prescribe the specific means by which regulatory requirements are to be complied with. However, the point of departure for principle-based regulation is the fact that the principles are drafted as high-level rules that are applied as overarching requirements in a broad range of circumstances, rather than particular standards or outcomes that apply in a particular case or scenario. For example in the UK, ALARP [20], and so far as is reasonably practicable (SFAIRP) principles are widely applied and the licensee understands that there is a dose limit to radiation from the reactors that members of the public can tolerate and this limit cannot be exceeded. Furthermore, the principles are likely to be couched in qualitative terms, whereas performance-based standards may be quantitative in nature.
In South Africa and the USA, nuclear safety is underpinned by the "as low as reasonably achievable (ALARA), taking into account economic and societal factors or lies at the heart of radiation safety" principle, which directs the way in which the regulatory provisions are applied. The objective of this principle is to ensure that all preventive measures to reduce radiation exposure are implemented as long as they do not do more harm than good. Because of its qualitative nature, ALARA lies at the heart of deterministic analyses where "safe enough" answers are acceptable rather than in probabilistic analyses.

Principle-based regulation shares many of the advantages associated with PBR. In particular, this type of regulation is relatively flexible and may be a cost-effective way to achieve regulatory objectives. It may also allow the regulatory framework to respond to changes in the broader practical context in which it is applied. However, ambiguity regarding the application of principles in the array of circumstances to which the regulatory framework applies may pose particular problems for compliance and enforcement.

\subsubsection{Risk-based Regime}

The traditional approaches to regulation, apart from nuclear regulations, entail the exertion of regulatory authority through a system of rules and laws in which the regulator ensures technical compliance by the nuclear licensee. Scholars of public administration and governance perceive the traditional regulatory regime as reactive and a focusing more on enforcement rather than assisting the licensee to comply with the requirements. It is believed that they often miss the critical emerging risks because they are seen as being outside of jurisdiction, with regulators often being slow in their response. According to Hutter [25], there is no firm definition of risk-based regulation, but the practice generally includes a commitment to a philosophy which takes the principles of risk management as a framework for governance. It (i.e. risk-based regulation) involves the fusion of regulations with technical processes/systems by employing the technical risk-based tools normally employed in economics (e.g. cost-benefit approaches) and science/engineering (e.g. risk assessment techniques). According to Nicholls [29], it therefore involves a repetitive risk analysis, which is summarised by Figure 3. Cycle of risk-based regulation $[25,26]$. 


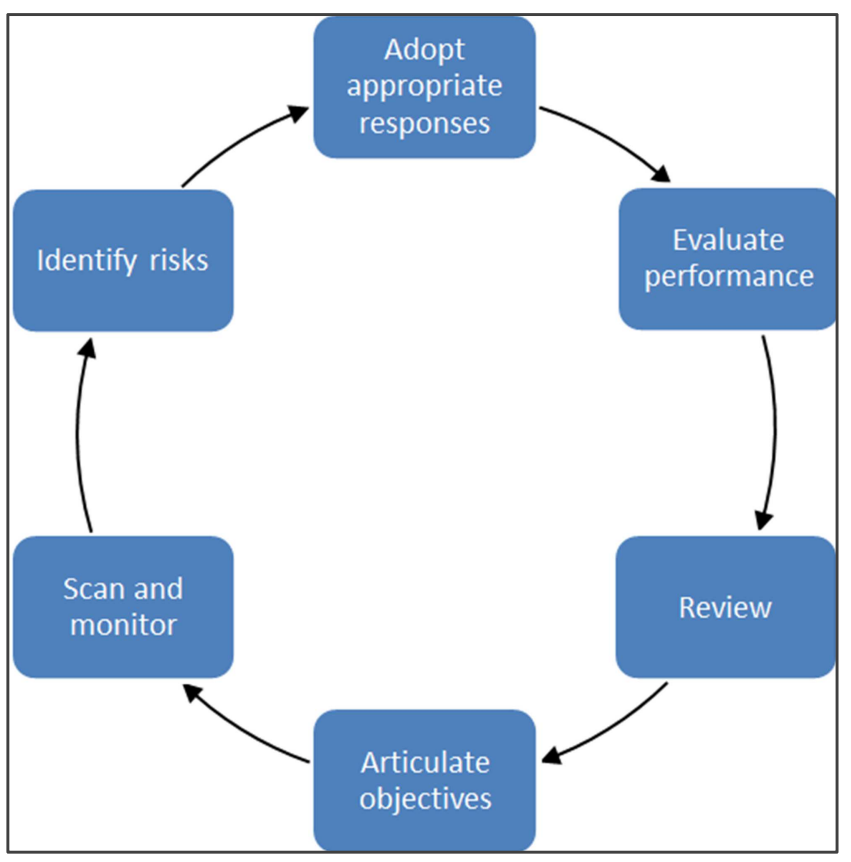

Figure 3. Cycle of risk-based regulation.

Risks are identified and assessed, a ranking or score is assigned on the basis of this assessment, and inspection and enforcement are undertaken on the basis of these scores. It can therefore be described as a holistic approach which encompasses regulation (e.g. nuclear regulations) and risk management. It provides an overarching framework for governance compared to regulatory systems where risk management tools are used in a piecemeal way; for example, those which rely more on the expertise of individual regulatory officials or local offices and regimes. Because traditional regulatory regimes exert far too much authority over the licensee, a more modern regulatory approach has emerged in recent years in the nuclear industry a 'risk-based', 'risk-informed 'and 'hazard-informed' regulatory approach, which seeks to: i) address the shortcomings of traditional regulations in the nuclear industry because of safety concerns; and ii) eliminate all the unnecessary generic processes associated with other industries. This is specifically suited to the nuclear industry but has been adopted by other economic sectors as well.

Risk-informed and hazard-informed approaches are used by regulators to determine the risk or hazard associated with an issue in order to evaluate the appropriate level of regulatory attention [8, 27]. Although risk-informed and hazard-informed may appear the same to non-scientists, to a nuclear licensing engineer they are not in that:

1) A risk-informed approach uses a specific methodology including probability and potential for harm to identify areas of greatest risk.

2) A hazard-informed approach uses specific criteria for the identification of areas with the greatest potential for harm.

A major benefit of risk- and hazard-informed approaches is that they focus regulatory attention by prioritising safety issues and allocating resources. Potential difficulties for regulators using these approaches include the possibility of overlooking the limitations of risk and hazard analysis methods, which may then result in some regulatory areas receiving either inadequate or too much attention. Risk analyses applied in the risk-based and risk-informed regulatory approaches referred to may be divided into two main categories, deterministic and probabilistic analyses, which are described below.

\section{(i). Deterministic Probabilistic Approaches}

Deterministic analysis in the nuclear regulatory process does not exclude safety considerations; it takes into account, implicitly or explicitly, various scenarios and their consequences in order to establish a reasonable margin of safety, which corresponds to a multiple of the maximum safety risk that the installation would have to sustain. Therefore, conservative design based on deterministic analysis is indeed very important for safety analyses.

\section{(ii). Probabilistic Approaches}

Probabilistic analysis, on the other hand, explicitly takes into account the likelihood of the various adverse scenarios and ranks them on the basis of severity or probability of occurrence, also known as frequency. Credit must be given to a rational process (called probabilistic risk analysis (PRA) in the nuclear industry, where the concepts and tools originated, and quantitative risk analysis (QRA) in other industries), the risk level associated with a specific design or with risk mitigation measures can be determined. It therefore becomes possible to optimise the design of an installation. It should be noted that the optimised overall risk level of riskbased design is not necessarily lower than that of a deterministic-based design for at least two reasons: first, a conservative design may induce points of weakness in parts of the installation which can be overlooked, and second, as a conservative design may be unnecessarily expensive, this could prevent the implementation of potentially beneficial risk-abatement measures in other areas. To sum up, the risk level in a deterministic approach remains implicit, whereas in a probabilistic approach it is explicitly specified.

As stated before, the traditional regulatory approach (prescriptive and non-prescriptive) would be one where nuclear regulators prescribe technical solutions based on deterministic calculations. This makes up by far the largest number of regulations nowadays in any industry. At the opposite end of the spectrum, a non-prescriptive such as a performance-based approach, rooted in probabilistic calculations, corresponds to a pure risk-based approach. From that perspective, regulations have to rely on a joint effort/partnership between the nuclear regulators and the licensee: nuclear regulators have to set the standards to be reached (e.g. the risk acceptance criteria), or the process to be followed to establish these standards, and the licensees have to develop the means to reach them. However, a prescriptive approach based on probabilistic calculations could of course still be adopted in which the nuclear regulator would impose the technical solutions to be used by the licensee, based on the insights it would have gained from 
the use of risk analysis.

Finally, a performance-based approach could rely on deterministic considerations; this approach may be found where the level of performance to be reached can be expressed in deterministic terms. In that case, it implies that measurable or calculable indicators exist which enable the regulator to monitor the system performance, and then in turn show that it operates safely. These basic combinations can be completed by the possibility of substitution rules, i.e. when the requirements of a prescriptive regulation can be allowed to be fulfilled by a solution other than the prescribed one. In that respect, a prescriptive regulation (based on deterministic or probabilistic foundations) can be complemented with a substitution rule (based on deterministic or probabilistic foundations), which enables the licensee to choose between standard compliance and a performance-based system. In that case the burden of proof shifts to the regulator, which has to prove that the licensee has failed to comply with the requirements. There is no question that these two basic combinations resort to what is usually classified as prescriptive and risk-based approaches to regulation respectively, but when used in combined they constitute what is called a hybrid regulatory approach.

My proposal, however, is to categorise them (i.e. deterministic and PRA) into the risk-based regulations category seeing that they incorporate elements that do not resort under traditional, command-and-control regulations. The justification for this distinction is based on the grounds that one of the central questions in this research paper is to establish whether regulators should, in the interests of safety and energy security, adopt new regulatory approaches where nuclear safety is explicitly built into the design and apply the novel risk-based approach rather than the reactive standard prescriptive approaches.

\subsection{The Dilemma of Choosing Between ALARA or ALARP-based Regulatory Principle}

Nuclear entities, including nuclear regulators are often unsure which of the two principle i.e. ALARA or ALARP to adopt as the basis of their safety policy, as a result they end up selecting what sounds more common or familiar. The source of this confusion is largely because of lack of understanding what each of these concepts really mean which will be explained below. ALARA stems from the three ICRP-103 basic principles [22, 28]:

a. The principle of justification: Any decision that alters the radiation exposure situation should do more good than harm.

b. The principle of optimisation of protection. The likelihood of incurring exposure, the number of people exposed and the magnitude of their individual doses should all be kept as low as reasonably achievable, taking into account economic and societal factors.

c. The principle of application of dose limits: The total dose to any individual from regulated sources in planned exposure situations, other than medical exposure of patients, should not exceed the appropriate limits specified by the ICRP.

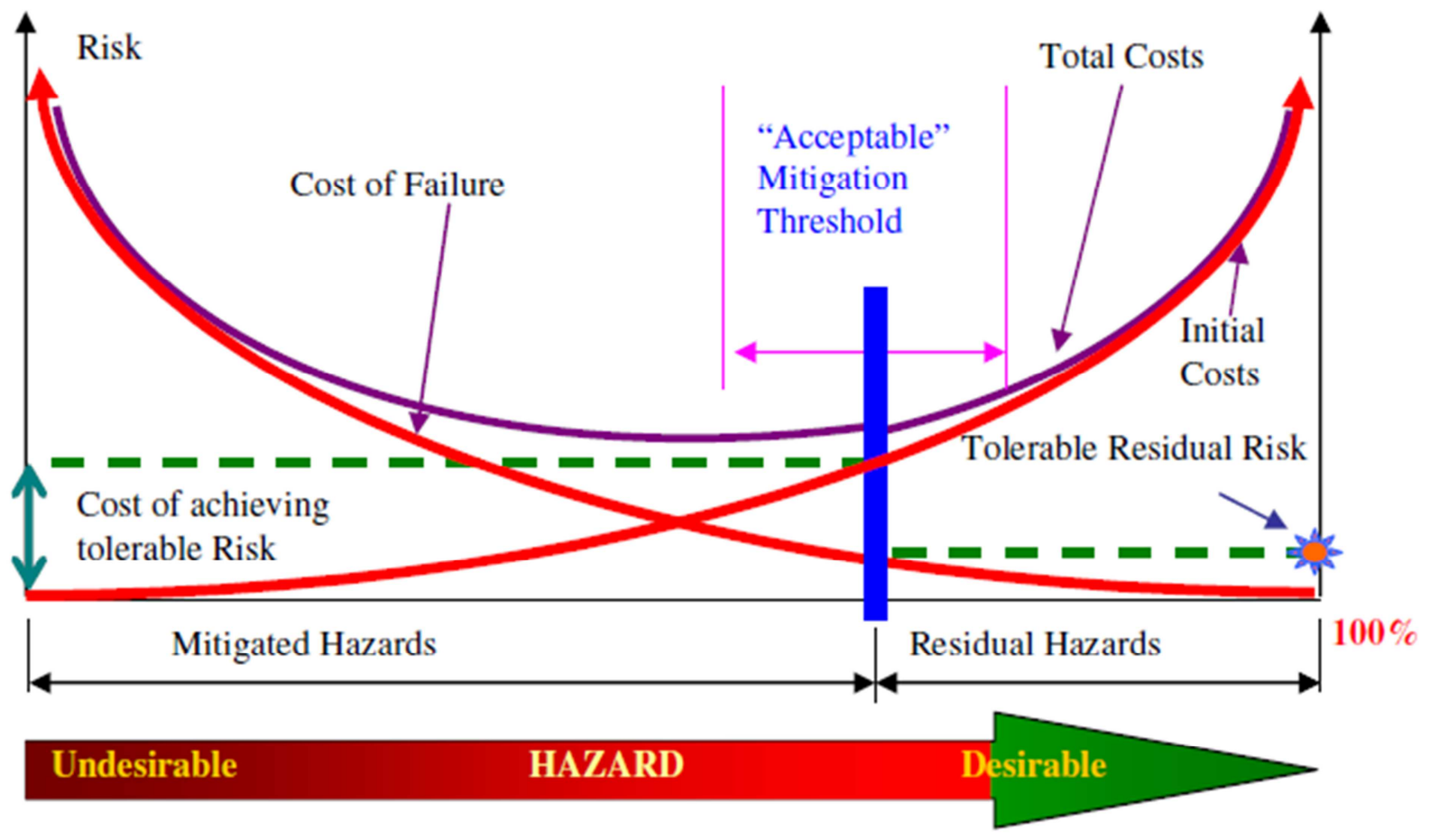

Figure 4. Risk and its mitigation costs.

The description of the optimisation of protection, which introduced the term ALARA, focuses on individual doses and refers to risks assessed using the dose/risk relationship recommended by the ICRP. ALARA has proved to be an 
effective tool for managing human risks after low dose exposures, taking into account individual doses, the number of exposed individuals and the likelihood that an exposure situation will occur. Based on ICRP recommendations, a linear relationship between the risk of harmful effects and the radiation dose is assumed at low doses. Theoretically, the dose can always be further reduced, however, this will lead to increased cost. Accordingly, there is an optimum protection level in terms of additional risk and cost. ${ }^{10}$ ALARA as it is currently formulated by the ICRP focuses on optimising the protection of humans, not explicitly considering possible effects on non-human species. The three ALARA principles in the ICRP recommendations were adopted in the IAEA Basic Safety Standards (BSS) directive and were subsequently transcribed into UK health and safety legislation using the terms ALARP (as low as reasonably practicable) and SFAIRP (so far as is reasonably practicable). Hence, in for the purposes of radiation protection legislation, ALARP and SFAIRP can be regarded as essentially the same in terms of requirements.

The ALARP principle, on the other hand, is a form of risk acceptance criteria used in the UK by the HSE by means of which organisations weigh the risk against the resources needed to implement the corresponding risk-abatement measures (refer Figure 4. Risk and its mitigation costs. [29] Before then, there has to be a technique to define/identify risk and then criteria to rank whether it is acceptable or not.

It will therefore be noticed that in ALARP, the cost of dose abatement is a key factor in deciding whether the dose reduction measures are undertaken or not where as in ALARA the cost factor does not feature as much but rather the dose and health risk.

Figure 4 demonstrates the decrease in risk against increasing costs of eliminating hazards. The solid red curve sloping upward from an undesirable to a desirable state shows the cost of eliminating hazards. The other solid red curve sloping in the reverse direction shows the cost of cleanup/remedial action if something went wrong. The summation of these two curves gives the total cost of eliminating all hazards. When risks are very high, a relatively small investment generally allows risks to be reduced quickly, whereas investments increase asymptotically when risks are reduced beyond a certain level. The graph shows the point at which an acceptable threshold of risk mitigation might be settled, stating explicitly that the costs of mitigation will realistically be too high to achieve a theoretical total abatement of risk. The blue vertical line is set in the ALARP/ALARA zone, i.e. a zone where risks are as low as reasonably achievable (ALARA) and as low as reasonably practical (ALARP).

\subsubsection{Risk Tolerance and Risk Acceptance}

Risk management is about balancing the benefits of risk being reduced against the probability of consequences from risk not being addressed. Risk events, when presented, can be

10 Note that in ALARA cost is implied, whereas in ALARP cost is explicit. simplistically viewed as either broadly acceptable, or tolerable, or broadly unacceptable. Generally, there is a range presented between acceptable and unacceptable risk (refer Figure 5). While the risk in this tolerable risk zone is not acceptable, for many cases significant resources and/or technology and/or know-how will be within a broadly acceptable zone. The zone between the unacceptable and broadly acceptable regions is the tolerable region [30]. Risk tolerance is the willingness to bear a certain risk to obtain certain benefits with the confidence that the risk has been controlled, is being reviewed, or will be reduced in the future. Risk acceptance refers to consent to and to accept the level of risk present in an activity, assuming no changes in the risk control mechanisms. However, it should be borne in mind that the use of the term risk acceptance should not be interpreted as implying or giving licence to avoid implementing necessary preventive, mitigation and response actions in order to eliminate and control activities with significant levels of risk.

\subsubsection{Establishment of Risk Acceptance Criteria}

Risk acceptance criteria are the basis for decision-making about accepting risk. Regulatory authorities across the world adopt different approaches to establish the risk acceptance criteria that suit the industry and the technology they are regulating, taking into consideration the socioeconomic situation they operate in. The criteria can generally be classified according to three 'pure' criteria, and regulators can either use these criteria on their own or in combination with others to develop new criteria. These criteria are [30]:

1) Equity-based - the notion is that all individuals have unconditional rights to certain levels of protection. This often converts into fixing a limit to represent the maximum level of risk above which no individual can be exposed. If the risk is above this maximum limit and further control measures cannot reduce the risk, the risk is deemed to be unacceptable.

2) Utility-based - this approach measures risk reduction against cost. It compares the monetary value of benefits (e.g. statistical lives saved, life-years extended) with the cost of prevention measures for a particular risk. It also requires a particular balance to be maintained between the two.

3) Technology-based - this approach reflects the idea that the application of state-of-the-art technology gives an acceptable level of risk. In the South African context it makes a lot sense that, having decided that we will follow a nuclear programme as an addition to the energy mix, we weigh up the pro and cons of each technology available, for example pressurised water reactor (PWR), boiling water reactor (BWR) or high temperature gas cooled reactor (HGTR) or any of the above variants.

The overall process by which risk management is performed under the UK HSE, ALARP, is summarised in Figure 4. Under ALARP, risks are divided into three regions: broadly acceptable risk, intolerable risk, and tolerable if 
ALARP risk, as shown in Figure 5 [30].

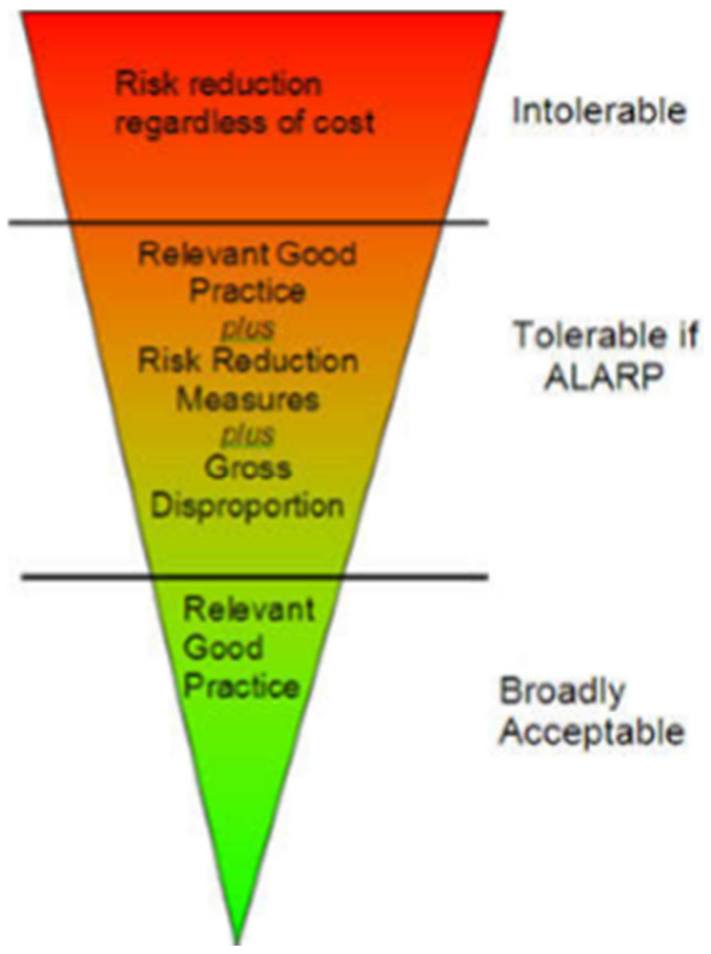

Figure 5. Levels of risk and ALARP.

The different categories indicated in Figure 5 are described below:

i. Broadly acceptable

Level of residual risk regarded as insignificant and further effort to reduce risk not likely to be required, as resources to reduce risks are likely to be grossly disproportionate to the risk reduction achieved.

ii. Tolerable risk

If residual risk remains in this region, and society desires the benefit of the activity, the residual risk is tolerable only if further risk reduction is impracticable or requires action that is grossly disproportionate in terms of time, trouble and effort to the reduction in risk achieved.

iii. Intolerable risk

Risk cannot be justified except in extraordinary circumstances. Even then, control measures must be introduced in order to drive the residual risk in this region towards the ALARP region.

\section{Evaluating the Effectiveness of a Nuclear Regulatory Authority}

Having established a nuclear regulatory authority and just because it is independent from all forms of influence; that on its own is not adequate in as far as nuclear safety public acceptance of nuclear is concerned. To that effect, the nuclear regulatory authority (regardless of whether it is National Nuclear Regulatory Authority or it is a licensee's internal nuclear licensing department) has to constantly evaluate itself to determine whether it is living up to the mandate it was developed for; to that effect it has to constantly evaluate its effectiveness in protecting the public and the environment from all forms of nuclear and radiological health risks. For the National Nuclear Regulatory Authority, this may call for subjecting and opening itself to external peer review by other nuclear regulatory authorities from other countries and international nuclear regulatory bodies such as Institute of Nuclear Power Operations (INPO), World Association of Nuclear Operators (WANO), and IAEA to determine how it is ranked internationally in nuclear regulatory affairs. As additional check, it must also be open assessment by its licensees or other nuclear public interest groups.

In addition to external peer review, it must also perform its own self-assessment using all the information it has at its disposal to rate its own performance against what it was established for. Strengthening internal controls like strengthening the effectiveness of internal regulatory body will further strengthen the effectiveness of a National Nuclear Regulatory Authority which will translate to a safer nuclear industry and a public that is safe and free from radiological health risks.

To evaluate the effectiveness of nuclear regulatory authority living up to its mandate, the following yardsticks are recommended, it, (i.e. the nuclear regulatory authority) needs to develop a list of performance measures and allocate a weighting factor to each which indicate the importance of that performance measure in the regulator achieving its effectiveness (refer Table 5). The higher the weighting factor linked with the performance measure, the more important that measure is and failure in that measures must lead to immediate action being taken, not to only bring the (emergency) situation under control but to restore the effectiveness of the regulator in providing a safe environment.

Table 5. Effectiveness measures for a nuclear Regulatory Authority.

\begin{tabular}{ll}
\hline National Regulatory Authority & \multicolumn{1}{|l}{$\begin{array}{l}\text { Ineffectiveness } \\
\text { scale }\end{array}$} \\
\hline Description & 8 \\
\hline $\begin{array}{l}\text { Nuclear accident }{ }^{11} \text { with fatalities, irrespective of whether } \\
\text { it is a DBA }{ }^{12} \text { or a BDBA }^{13} \text { irrespective of it grading in the } \\
\text { International Nuclear and Radiological Event Scale } \\
\text { (INES) }\end{array}$ & \\
$\begin{array}{l}\text { Nuclear Accident with no fatalities but requiring } \\
\text { relocation irrespective of it grading in the International }\end{array}$ & 7 \\
$\begin{array}{l}\text { Nuclear and Radiological Event Scale (INES) } \\
\text { The Nuclear regulator buckling under pressure of the } \\
\text { licensee }{ }^{14} \text {. }\end{array}$ & 6 \\
\hline
\end{tabular}

\footnotetext{
${ }^{11}$ Any unintended event, including operating errors, equipment failures and other mishaps, the consequences or potential consequences of which are not negligible from the point of view of protection and safety [40].

${ }^{12}$ DBA=Design Basis Accident: A postulated accident leading to accident conditions for which a facility is designed in accordance with established design criteria and conservative methodology, and for which releases of radioactive material are kept within acceptable limits.

${ }^{13}$ BDBA=Beyond Design Basis Accident: Postulated accident with accident conditions more severe than those of a design basis accident [40].

${ }^{14}$ This defeats the purpose of independence of the nuclear regulator.
} 


\begin{tabular}{|c|c|}
\hline \multicolumn{2}{|l|}{ National Regulatory Authority } \\
\hline Description & $\begin{array}{l}\text { Ineffectiveness } \\
\text { scale }\end{array}$ \\
\hline $\begin{array}{l}\text { Nuclear Accident with no fatalities but requiring } \\
\text { evacuation + distribution of } \mathrm{KI}^{15} / \mathrm{KIO}_{3} \text { pills }\end{array}$ & 5 \\
\hline Nuclear Incident ${ }^{16}$ warranting being reported to the IAEA & 4 \\
\hline $\begin{array}{l}\text { Nuclear incident due to failure to implement lessons } \\
\text { learnt from other NPPs }{ }^{17}\end{array}$ & 3 \\
\hline $\begin{array}{l}\text { Nuclear Incident not warranting being reported to the } \\
\text { IAEA }\end{array}$ & 2 \\
\hline Nuclear Event ${ }^{18}$ & 1 \\
\hline Licensee's Internal Nuclear Regulatory Department & \\
\hline $\begin{array}{l}\text { Anyone of the National Nuclear Regulatory Authority's } \\
\text { measures with a weighting factor from } 3 \text { upwards }\end{array}$ & 10 \\
\hline $\begin{array}{l}\text { Manager "twisting the arm" of an analyst to change the } \\
\text { analytical solution that would otherwise be not accepted } \\
\text { by the regulator to answer to what will accepted }\end{array}$ & \\
\hline $\begin{array}{l}\text { An analyst buckling under pressure from management to } \\
\text { change the correct analytical solution just because it is } \\
\text { not acceptable to management and the nuclear regulator } \\
\text { to what is "favourable" to management }\end{array}$ & \\
\hline Violation of Nuclear License & 9 \\
\hline Nuclear Incident warranting being reported to the & \\
\hline $\begin{array}{l}\text { National Nuclear Regulatory Authority within a } \\
\text { prescribed time frame }\end{array}$ & 8 \\
\hline Outright rejection of a submission & 7 \\
\hline Submission returned with one ${ }^{19}$ highest graded comments & 6 \\
\hline $\begin{array}{l}\text { Submission requiring more than } 2 \text { resubmission before it } \\
\text { is accepted by the National Nuclear Regulatory Authority }\end{array}$ & 5 \\
\hline $\begin{array}{l}\text { Regulator raising a second comment on the response to } \\
\text { the first comment. }\end{array}$ & 4 \\
\hline $\begin{array}{l}\text { Failure to adhere/apply scientific principles appropriately } \\
\text { in resolving the regulators comments. }\end{array}$ & 3 \\
\hline $\begin{array}{l}\text { Adopting/accepting the Nuclear Regulators } \\
\text { recommendations/comments and 'addressing' them } \\
\text { merely to just get the document accepted by the nuclear } \\
\text { regulator in spite of comment being scientifically } \\
\text { incorrect }^{20} \text {. }\end{array}$ & 2 \\
\hline $\begin{array}{l}\text { Submission Accepted but with negative comments on the } \\
\text { quality of a submission, e.g. editorial }\end{array}$ & 1 \\
\hline
\end{tabular}

\footnotetext{
${ }^{15} \mathrm{KI}=$ Potassium Iodide, $\mathrm{KIO}_{3}=$ Potassium Iodate.

${ }^{16}$ Any unintended event, including operating errors, equipment failures, initiating events, accident precursors, near misses or other mishaps, or unauthorized act, malicious or nonmalicious, the consequences or potential consequences of which are not negligible from the point of view of protection and safety [40].

${ }^{17}$ Nuclear Power Plants.

${ }^{18}$ In the context of the reporting and analysis of events, an event is any occurrence unintended by the operator, including operating error, equipment failure or other mishap, and deliberate action on the part of others, the consequences or potential consequences of which are not negligible from the point of view of protection and safety [40].

${ }^{19}$ Assuming all National Regulatory Authority's comments are graded in order of severity.

${ }^{20}$ It is important to note that in the business of nuclear licensing, nuclear safety is central to our business and NOT the number of documents that are passed through and accepted by the nuclear regulator. This is because not always does a document accepted or comments raised by the nuclear regulator translate/equate to safety. It is therefore unethical, unsafe and unprofessional to just 'give what the regulator what he wants so that this document can be accepted' as nuclear regulator's reviewer is also human and can make a mistake and make recommendations or comments that are scientifically incorrect. There is therefore no harm in showing the nuclear regulator these errors and discuss its potential safety impact (or lack thereof) instead of just 'giving the regulator what he wants to get the document accepted' and if he still insist to have these recommendations or comments addressed or implemented; plant safety comes first. You cannot implement a recommendation that puts everyone's health at risk nor are you obliged to 'address' comments that do not need to be 'addressed'.
}

\section{The Shift Towards Alternative Nuclear Regulatory Approaches: A Case Study of South Africa}

A brief description of the evolution of South Africa's nuclear regulatory regime was described [1], however a more detailed description is provided in this research to supplement the information given in the previous publication [1].

The nuclear licensing process in South Africa's nuclear industry began in 1963 through the Nuclear Installations (Licensing and Security) Act of 1963 (Act 43 of 1963) when nuclear licensing was passed, which stipulated that all nuclear installations had to be licensed by the Atomic Energy Board (AEB), including the AEB itself, which in today's regulatory terminology is known as self-regulation, which is not ideal $[31,32]$. Although this was hailed as a move in the right direction, it lacked the independence which, in today's regulatory requirements is one of the basic tenets of an effective nuclear regulatory authority. Because it is was prone to influence by the licensee it was not entirely objective and effective in carrying out its regulatory functions, which in today's NNR mandate means protecting people, environment and property [18]. Looking at the Act that was in force when the construction of Koeberg began in 1976 and up to 1984 when the first unit (Unit 1) was commissioned, one can only infer that Koeberg was licensed by the AEB under the Nuclear Installations (Licensing and Security) Act. In 1970, the AEB started a process of moving towards becoming an independent nuclear regulator. A licensing section was established which was functionally separated from other AEB nuclear activities and a Nuclear Safety Advisory Committee was appointed to oversee nuclear licensing matters. The functions of the licensing section were to perform the scientific technical function associated with nuclear regulatory control of safety. The self-regulation continued until 1982 when the Energy Act of 1982 was promulgated. Subsequently, the AEB was amended and renamed the Atomic Energy Corporation (AEC) but retained its nuclear regulatory function under a new separate quasiindependent regulatory authority, the Council for Nuclear Safety (CNS), which replaced the Nuclear Safety Advisory Committee.

In 1988, through the Nuclear Energy Amendment Act (Act 56 of 1988), the CNS became an autonomous, independent juristic person which allowed it to acquire its own property. This gave the CNS the regulatory independence that is expected of every nuclear regulatory authority globally.

In 1999, the Nuclear Energy Act (Act No. 46 of 1999) was enacted by the Parliament of South Africa for the "Establishment of South African Nuclear Energy Corporation, Limited" to replace the AEC which in Chapter 11 its states;

3. (1) There is hereby established a nuclear energy corporation for the Republic which will be a juristic person. (2) Despite the provisions of the Companies Act or any other law, that corporation, with effect from the 
specified date, will be a public company incorporated in accordance with section 4. (3) The main objects of that corporation and, accordingly, those of that company, are to perform the functions mentioned in section 13.

The preamble to the Act reads as follows [33].

To provide for the establishment of the South African Nuclear Energy Corporation Limited, a public company wholly owned by the State (the "Corporation"), to define the Corporation's functions and powers and its financial and operational accountability, and provide for its governance and management by a board of directors and a chief executive officer; to provide for responsibilities for the implementation and application of the Safeguards Agreement and any additional protocols entered into by the Republic and the International Atomic Energy Agency in support of the Nuclear Non-Proliferation Treaty acceded to by the Republic; to regulate the acquisition and possession of nuclear fuel, certain nuclear and related material and certain related equipment, as well as the importation and exportation of, and certain other acts and activities relating to, that fuel, material and equipment in order to comply with the international obligations of the Republic; to prescribe measures regarding the discarding of radioactive waste and the storage of irradiated nuclear fuel; and to provide for incidental matters [33].

The large majority of senior and other technical staff had had experience of the British nuclear regulatory authority by virtue of their nuclear experience at UK nuclear power plants.

As such, they had gained a wealth of experience from UK regulatory authorities such as the National Radiological Protection Board (NRPB), the ONR and the HSE. Because of this, in the beginning the CNS leant more towards the British nuclear regulatory regime, which is why it started off as nonprescriptive. As CNS staff became more involved in various international nuclear regulatory affairs, such as participating in various committees and working groups of the IAEA, there was a cross pollination with other nuclear regulatory bodies in other countries, notably the US nuclear regulatory commission (NRC). As a result, there was a gradual migration from a non-prescriptive to a prescriptive regime. Right now, the NNR (which succeeded CNS) tends to take a hybrid regime with greater influence from a non-prescriptive rather than a prescriptive regulatory approach. When I joined the CNS in the second half of 1995, the CEO was Bert Winkler, Jeff Leaver was the General Manager, Phil Metcalf the Senior Manager for Power Reactors and Sam Parish Senior Manager for Mining and Mineral Processing (MIMPS) (refer Figure 6). They were based in Centurion, Tshwane [1]. In 1993, the Nuclear Energy Act was promulgated with a view:

To provide for the continued existence of the Atomic Energy Corporation of South Africa, Limited, and of the Council for Nuclear Safety and for the management thereof; to determine the objects, powers and functions of that Corporation and that Council; to provide for the implementation of the Nuclear Non-Proliferation Treaty and the Safeguards Agreement; to regulate the licensing of nuclear activities; to amend the Hazardous Substances Act, 1973, so as to amend a certain definition; and to provide for matters connected therewith [34].

This Act made provision for the continuation of the CNS as a juristic person:

The Council for Nuclear Safety established by section 24 of the Nuclear Energy Act, 1982 (Act No. 92 of 1982), shall continue as a juristic person known as the CNS, notwithstanding the repeal of that Act by this Act. [34]

The objects of the CNS are, with a view to the safeguarding of persons against nuclear damage, to regulate and exercise control, through the issue of nuclear licences or the exercise of the discretion contemplated in section 51 (1), over-

a. the construction or use of a nuclear installation;

b. the use, possession, production, storage, processing, enriching,

c. reprocessing, conveyance or disposal of radioactive material;

d. the discarding of radioactive waste; and

e. the storage of irradiated nuclear fuel;

f. the carrying out of any other activity involving radioactive material and which is capable of causing nuclear damage.

During these years, the nuclear regulatory methodology of the CNS was largely non-prescriptive, specifically performance-based, depending largely on the operational experience of other countries and also advice from the IAEA.

In 1999, the same year of enactment of Act for Establishment NECSA, the National Nuclear Regulator Act (the NNR Act) (Act 47 of $1999^{21}$ ) was enacted with a view to providing for the establishment of National Nuclear Regulator (NNR) by virtue of Chapter 2 paragraph 3 of the NNR Act, which reads: "A juristic person to be known as the National Nuclear Regulator, comprising a board, a chief executive officer and staff, is hereby established" [18]. In addition, paragraph 4 of Chapter 2 of the NNR Act gave effect for the transfer of assets of the CNS to NNR and reads as follows:

(1) On the specified date, all assets, rights, liabilities and obligations of the Council for Nuclear Safety pass to the Regulator.(2) The Registrar of Deeds concerned must make such entries or endorsements as are necessary to give effect to subsection (1) in or on any relevant register, title deed or any other document in his or her office or submitted to him or her.(3) No office fees or other moneys are payable in respect of such an entry or endorsement.

Consequently, the NNR was established and its objectives are listed below;

The objects of the Regulator are to-

a. provide for the protection of persons, property and the

21 its preamble reads: "To provide for the establishment of a National Nuclear Regulator in order to regulate nuclear activities, for its objects and functions, for the manner in which it is to be managed and for its staff matters; to provide for safety standards and Nuclear Regulatory practices for protection of persons, property and the environment against nuclear damage; and to provide for matters connected therewith" [26]. 
environment against nuclear damage through the establishment of safety standards and regulatory practices;

b. exercise regulatory control related to safety over-

i. the siting, design, construction, operation, manufacture of component parts, and decontamination, decommissioning and closure of nuclear installations; and

ii. (vessels propelled by nuclear power or having radioactive material on-board which is capable of causing nuclear damage, through the granting of nuclear authorisations;

c. exercise regulatory control over other actions, to which this Act applies, through the granting of nuclear authorisations;

d. provide assurance of compliance with the conditions of nuclear authorisations through the implementation of a system of compliance inspections;

e. fulfil national obligations in respect of international legal instruments concerning nuclear safety; and

f. ensure that provisions for nuclear emergency planning are in place.

The migration/transition from non-prescriptive to prescriptive was largely influenced by the relationship that the CNS established over the years with the US Nuclear Regulatory Commission (USNRC), which was largely because the CNS was a fairly new organisation and needed an experienced organisation to hold its hand as it grew its expertise. The real benefit of this friendship with the NRC rather than the UK regulatory bodies, the NRPB, the ONR and the HSE, was that the NRC had already had many nuclear licensing documents which the CNS could access which neither the NRPB nor the ONR could provide, at least not to the extent the NRC could. As a result of this migration a number of licensing guides (LG) were developed and also laid the foundations for the development of nuclear regulatory guides (RGs) which to date (in 2020) are still being developed with a view to giving guidance to the licensee what will be acceptable to the NNR (that is, if the licensee followed the recommended process, it is assumed that they will arrive at the regulator's acceptable safety target). One of such process which was prescribed to licensees is the Formant and Content of the Safety Case, which was originally taken from the IAEA and was excellently incorporated into the NNR Nuclear Regulatory Guide 11 (RG-0011) [25]. This was of huge benefit to licensees in that it provided at least a minimum standard in the form of a process or system to be followed that would be acceptable to the nuclear regulator. This is much better than having nothing and just grabbing any IAEA document and using it in the hope that the regulator will be satisfied, thus taking a shot in the dark.

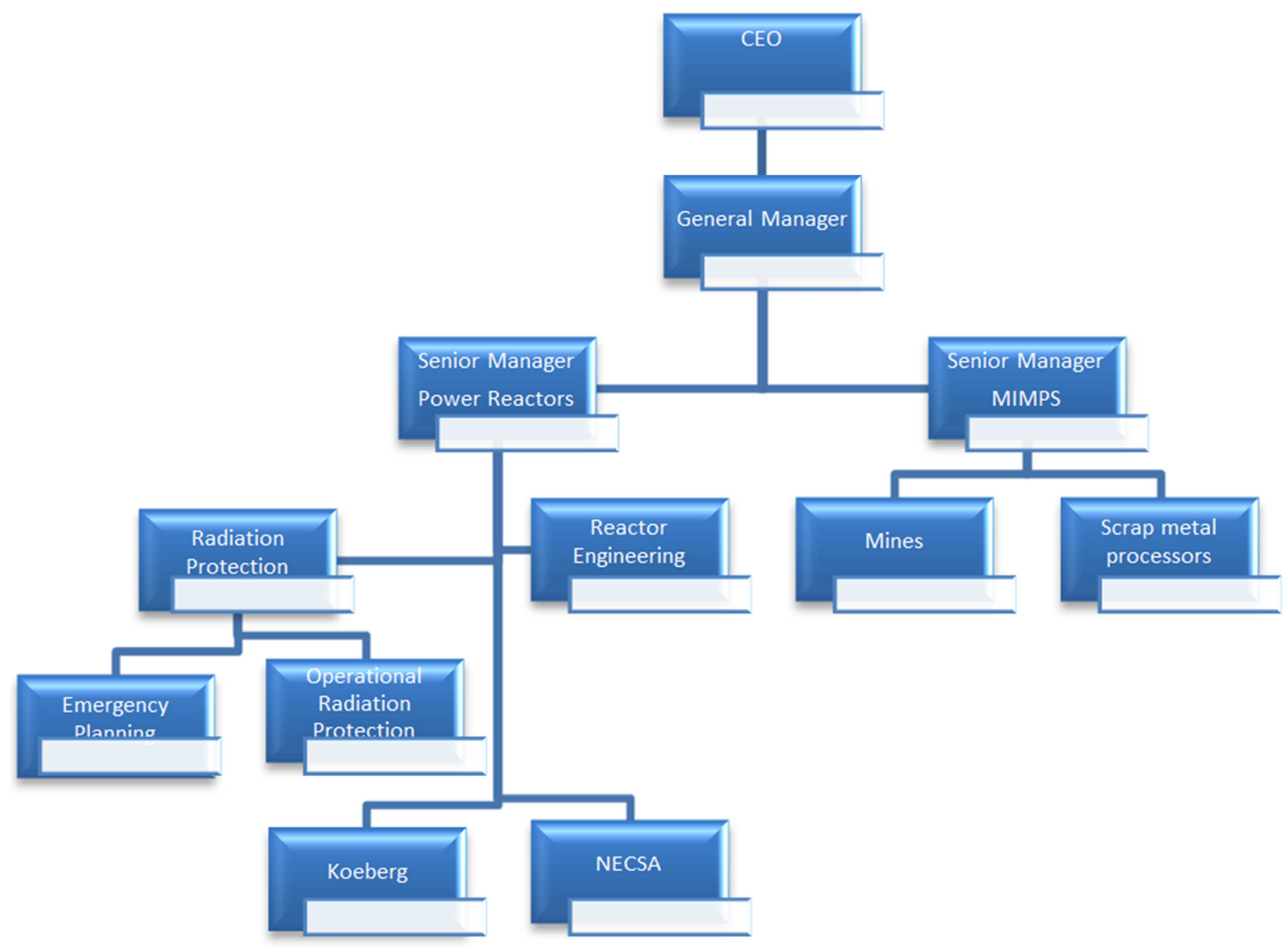

Figure 6. Organisation structure for CNS after its inception. 


\section{Conclusion}

If the nation is to prevent catastrophic nuclear accident and protect itself from the severe health effects of radiations it must have an effective nuclear regulatory authority that is completely independent and has all the necessary resources and skills it needs to perform its functions effectively, efficiently and in an unbiased way and is based on a firm legislative foundation. It is therefore not an ideal situation that a state organ that is responsible to promote nuclear energy is also the same state organ that is charged with the responsibility to regulate and promote nuclear safety. That is the case in South Africa where the responsibility of promoting nuclear energy lies with the department of mineral resources and energy (DMRE) and the same department is also charged with the responsibility for nuclear safety except that nuclear licensing/regulatory function is delegated to NNR. The same Ministry headed by Minister Gwede Mantashe is responsible for both; promoting nuclear energy as well as regulating the nuclear industry via NNR. This defeats the purpose of NNR being 'effectively independent' because on nuclear safety matters they report to the same Minister via the same department.

Similarly, the licensee must have its own mini/internal nuclear licensing department which is independent from the departments it is regulating/licensing, i.e. it cannot report to the general/senior manager to whom engineering or operations reports because of conflict of interest. The reporting level must be as high as the chief nuclear officer or chief operating officer so that it is completely free from the influence of the 'licensees', i.e. the departments it is regulating. In addition to that, it must be the only point of contact with the national nuclear regulatory authority.

It has to be emphasized that independence of the regulator on its own is not adequate to protect the public, environment and property. Independence of the regulator merely means the nuclear regulator has legislated powers and authority to perform the functions it was established for. The real value of the nuclear regulator in the society lies in its effectiveness to carry out its functions as mandated by the legislation. Effectiveness stretches beyond just the nuclear regulators being independent; it calls for the nuclear regulator to have a backbone and teeth and use its independence to stand firm on its decision, no matter how difficult it can be on the licensees. That takes commitment from principled, ethical, not-conflicted men and women nuclear professional; regardless of their position in the organization to standup for what is right regardless of repercussion. It calls for people not buckle under pressure and reverse the original decision they made before if it is backed up by evidence and science and if it was correct and would save the public from radiological health risks emanating from operation of a nuclear facility. The evidence of effectiveness of the nuclear regulators would be the reduction of the number of nuclear events, incidents and accidents that are observed in the nuclear facility. The high frequency of nuclear events, incidents and accidents that have been seen in the past half century in spite of the independence of nuclear regulator is a clear sign that the nuclear regulator is not effective in its nuclear regulatory affairs and just making a nuclear regulator 'independent' has proven to be inadequate. Public acceptance is the spin-off of an effective nuclear regulator when the public trusts that the nuclear regulator is there for them and not for the nuclear industry. Until this is addressed adequately; you can spend as much time and money in stakeholder engagement/management as you like it will not yield the results you like.

To that effect it is recommended that a new tool is developed (refer Table 5) to assess the effectiveness of the nuclear regulator in effecting its mandate.

On the question of choosing precisely what type of novel regulation (full risk-based, deterministic /performanceoriented, probabilistic / prescriptive, substitution rules) the nuclear regulatory authority should adopt depends socioeconomic developmental stage of the country and how established the safety culture of the organisation is.

ALARA and ALARP are not quite the same thing and should not be used interchangeably. The main difference between them is that ALARA is based on the dose/risk relationship and therefore exhibits a linear relationship (cost is implied), while ALARP is based risk vs the cost of reducing the risk, i.e. risk/cost relationship (cost is explicitly stated). ALARP is thus the outcome of cost-benefit analysis and is non-linear as was shown in Figure 4. The national government must therefore decide whether $\mathrm{s} / \mathrm{he}$ will provide the nuclear regulator with a blank cheque and ask them to reduce the dose regardless of how much it costs in which case he must adopt the ALARA principle or will prescribe a cap/limit on the cost of dose reduction measures and thus adopt the ALARP principle.

The cost factor is huge consideration when deciding on the decommissioning strategy of a nuclear plant if the site is to be returned to unrestricted use.

\section{References}

[1] Evolution of South African Nuclear Regulatory regime from the British Nuclear Regulatory System. Leotlela, M. J. 1, 2017, Journal of Modern and Applied Physics, Vol. 1.

[2] Regulatory Regimes and accountability. May, Peter J. 2007, Journal compilation, pp. 8-26.

[3] Bacon-Dussault, Malaika. Independence of Nuclear Regulators in the Aftermath of the Fukushima Daiichi Nuclear Accident: A comparative approach. Ottawa: Canadian Nuclear Safety Commission, 2011.

[4] UN. United Nations Secretariat Climate Action Plan 20-30. s.1.: United Nations, 2019.

[5] Energy, Department of. INTEGRATED RESOURCE PLAN FOR ELECTRICITY (IRP) 2010-2030. Pretoria: s.n., 2013.

[6] World Nuclear Association. World Nuclear Performance Report 2019. s.1.: World Nuclear Association, 2019. 
[7] IAEA. Governmental, Legal and Regulatory Framework for Safety, No. GSR Part 1 (Rev. 1): GENERAL SAFETY REQUIREMENTS. Vienna: IAEA, 2016.

[8] NEA-OECD. The Characteristics of an Effective Nuclear Regulator (NEA No. 7185). s.1.: NEA, 2014. p. 9.

[9] Clement, C. H. Environmental Protection: Transfer Parameters for Reference Animals and Plants. s.l.: International Commission of Radiological Protection, 2009. ICRP-114.

[10] Clement, C. H: Environmental Protection: The Concept and use of Reference Animals and Plants. s.1.: Pergamon, 2009.

[11] IAEA. Safety Culture. Vienna: IAEA, 1991.

[12] IAEA. Managing Regulatory Body Comptence. Vienna: IAEA, 2013. Safety Series Report No. 79.

[13] IAEA. Training the staff of the regulatory for nuclear facilities: A competency framework. Vienna: IAEA, 2001.

[14] Management-Based Regulation: Prescribing Private Management to Achieve Public Goals. Coglianese, Cary and Lazer, David. 4, 2003, Journal of the law and society association, Vol. 37, pp. 691-730.

[15] Regulations and Regulatory Governance. Levi-Faur, David s.l.: Researchgate, 2010, Jerusalem Papers in Regulation \& Governance.

[16] May, Peter J and Matthews, Donald R. Performance-Based Regulation. Jerusalem Papers in Regulation \& Governance. Jerusalem: s.n., April 2010. 2079-5882.

[17] Business-Report. Court strikes down Koeberg exclusion rule. [Online] 2007. [Cited: 16 July 2020.] https://www.iol.co.za/business-report/economy/court-strikesdown-koeberg-exclusion-rule-716172.

[18] DME. NNR Act, Act 47 of 1999. Pretoria: Department of Minerals and Energy, 1999.

[19] Prescriptive and Risk-Based Approaches to Regulation: The Case of FPSOs in Deepwater Gulf of Mexico. Lassagne, Marc G, Pang, David X and Vieira, Raul. Houston, Texas: Offshore Technology Conference, 2001.

[20] Office for Nuclear Regulations. A guide to Nuclear Regulation in the UK. s.l.: Office for Nuclear Regulation, 2016.

[21] BREDIMAS, Alexandre and NUTTALL, William J. A Comparison of International Regulatory Organizations and Licensing Procedures for New Nuclear Power Plants. Cambridge: Judge Business School, University of Cambridge, 2000.

[22] IAEA. Radiation Protection and Safety of Radiation Sources: International Basic Safety Standards.

[23] Maddocks. The Role Of Regulation In Facilitating Or Constraining Adaptation To Climate Change For Australian Infrastructure: Report for the Department of Climate Change and Energy Efficiency. Melbourn: Tudor RP, 2011.
[24] AEE. PERFORMANCE-BASED REGULATION: Aligning utility incentives with policy objectives and customer benefits. s.1.: ADVANCED ENERGY ECONOMY, 2018.

[25] Hutter, Bridget M. What Makes a Regulator Excellent? s.1.: London School of Economics and Political Science, 2015.

[26] The Challenges and Benefits of Risk-Based Regulation in Achieving Scheme Outcomes. Nicholls, Andrew. Adelaide: s.n., 2015.

[27] Brember, Peter, Ledgerwood, Ken and Mactaggart, Fiona. A Review of the Application of 'Best Practicable Means' within a Regulatory Framework for Managing Radioactive Wastes. Scottish and Northern Ireland Forum For Environmental Research (SNIFFER). 2005. Project UKRSR05.

[28] VALENTIN, J. The 2007 Recommendations of the International Commission on Radiological Protection. Recommendations.

[29] The ALARP Argument. Yasseri, Sirous. London: Brunel University, 2013.

[30] Quddus, Noor. Risk Acceptance Criteria: Overview of ALARP and Similar Methodologies as Practiced Worldwide. 2020.

[31] Marquard, Andrew. Origins and Development of South African Energy Policy. Thesis presented for the Degree of Doctor of Philosophy. s.l.: University of Cape Towm, 2006.

[32] NNR. National Nuclear Regulator Overview Of Strategic Objectives. Pretoria: National Nuclear Regulator.

[33] Parliament. NUCLEAR ENERGY ACT, Act 46 of 1999. Pretoria: s.n., 1999.

[34] Office, President. No. 131 of 1993: Nuclear Energy Act, 1993. Pretoria: Parliament of South Africa, 1993.

[35] NNR. INTERIM GUIDANCE FOR THE SITING OF NUCLEAR FACILITIES-RG-0011, Rev 0. Pretoria: NNR, 2012.

[36] South African Parliament. Nuclear Energy Act, 1993. Pretoria: s.n., 1993.

[37] Carrol, Peter, et al. Minding the Gap: Appraising the promise and performance of regulatory reform in Australia. Canberra: Published by ANU E Press, 2008.

[38] Emmerson, B W. Establishing an effective nuclear safety regulatory regime: Part 1 - Objectives and requirements. Nuclear Science And Technology, European Commission. Luxembourg: European Commission, 1994.

[39] Industry Radiological Protection Co-ordination Group (IRPCG). The Application of ALARP: A Nuclear Industry Good Practice Guide. 2012.

[40] IAEA. IAEA SAFETY GLOSSARY TERMINOLOGY USED IN NUCLEAR SAFETY. 